\title{
Communications
}

\section{Efficient and Selective Debromination of vic-Dibromides to Alkenes Using $\mathrm{CoCl}_{2} \cdot \mathbf{6 H} \mathrm{H}_{2} \mathrm{O} /$ Indium System}

\author{
Byung Woo Yoo, 'Seo Hee Kim, and Ga Hong Min \\ Department of Advanced Materials Chemistry, Korea University, Chungnam 339-700, Korea. E-mail: bwyoo@korea.ac.kr \\ Received September 11, 2011, Accepted November 3, 2011
}

Key Words : Debromination, Alkene, Cobalt chloride, Indium

The combination of halogenation and reductive dehalogenation is a useful step in the double bond protectiondeprotection strategy. ${ }^{1}$ Reductive debromination of vicdibromides with a variety of different agents has been the subject of many reports. However, most methods lack the desired chemoselectivity when other reducible functional groups are present and often require prolonged reaction times, or involve harsh reaction conditions. ${ }^{2}$ As a result, there is always considerable interest in the search for more efficient and selective procedures for the debromination of vic-dibromides. The reduction of $\mathrm{CoCl}_{2}$ to low-valent cobalt species and the synthetic utility of such species are well documented in the literature. ${ }^{3}$ Generally, reducing agents, such as zinc and magnesium, are used for the reduction of $\mathrm{CoCl}_{2}$. Because indium and zinc closely resemble each other in several aspects, including first ionization, we considered that a combination of $\mathrm{CoCl}_{2} \cdot 6 \mathrm{H}_{2} \mathrm{O}$ with indium could facilitate the reductive debromination of vic-dibromides under mild conditions. As in the case of zinc, the reduction potential of indium is not highly negative $\left(\mathrm{In}: \mathrm{E}^{\mathrm{o}}, \mathrm{In}^{+3} / \mathrm{In}=\right.$ $\left.-0.345 \mathrm{~V} ; \mathrm{Zn}: \mathrm{E}^{\mathrm{o}}, \mathrm{Zn}^{+2} / \mathrm{Zn}=-0.763 \mathrm{~V}\right)$ : thus, indium is not sensitive to water and does not form oxides readily in air. In recent years, indium metal has been the subject of active interest because of its unique properties such as low toxicity and high stability in water and air compared to other metals. ${ }^{4}$ In connection with our interest in exploring the utility of low-valent metal reagents for organic transformations, ${ }^{5}$ we herein wish to report an efficient and chemoselective method for the debromination of vic-dibromides $\mathbf{1}$ to alkenes $\mathbf{2}$ using $\mathrm{CoCl}_{2} \cdot 6 \mathrm{H}_{2} \mathrm{O} /$ indium system at room temperature. The reaction can be generalized as shown by eq. (1). Recently,

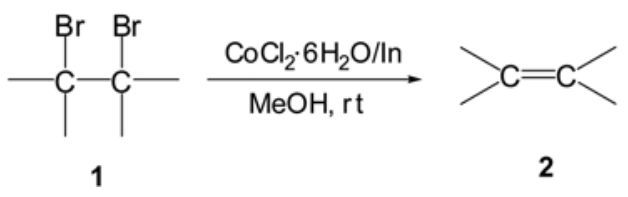

we reported the deoxygenation of various amine $N$-oxides using a $\mathrm{CoCl}_{2} \cdot 6 \mathrm{H}_{2} \mathrm{O} /$ indium system. ${ }^{6}$ To the best of our knowledge, this is the first study in which a $\mathrm{CoCl}_{2} \cdot 6 \mathrm{H}_{2} \mathrm{O} /$ indium system has been employed for the debromination of vic-dibromides. The new reducing system was generated by the addition of indium powder to a stirred solution of $\mathrm{CoCl}_{2} \cdot 6 \mathrm{H}_{2} \mathrm{O}$ in methanol under sonication. ${ }^{7}$ We investigated the reactions of the $\mathrm{CoCl}_{2} \cdot 6 \mathrm{H}_{2} \mathrm{O}$ /indium system with various vic-dibromides and observed that the debrominations generally proceeded with high yields and showed good selectivity over other labile substituents. In an attempt to characterize the low-valent cobalt species that presumably participates in the electron-transfer process, we conducted an experiment that showed that $\mathrm{CoCl}_{2} \cdot 6 \mathrm{H}_{2} \mathrm{O}$ was ineffective in debromination when no indium was present. We examined a series of functionally and structurally diverse vicdibromides and the representative results of the reactions are summarized in Table 1. Clearly a broad range of functional groups (ester, carboxyl, aldehyde, methoxy, bromo, chloro, and ketone) was tolerated under the reaction conditions. It is worth commenting that the sensitive carbonyl group remains intact without any further reduction (entries 4-10). In comparison with other procedures, the present procedure reduces vic-dibromides in higher yields and shows good chemoselectivity under mild conditions. The high yields of the debromination products demonstrate the efficiency of this new method. The notable advantages of this methodology are that it can be implemented under mild reaction conditions, reqires only simple manipulation, results in excellent yields, and retains several reducible functionalities. Furthermore, only trans olefins were obtained and no overreduction of the produced alkene was observed with any substrate. ${ }^{8}$ Although the reaction mechanism of the method has not yet been established, the reaction can be envisaged to proceed in two steps. In the first step, $\mathrm{CoCl}_{2} \cdot 6 \mathrm{H}_{2} \mathrm{O}$ is probably reduced by indium to form a low-valent cobalt species, which in the subsequent step would debrominate the vicdibromides $\mathbf{1}$ to give the corresponding alkenes $\mathbf{2}$ through a SET (single electron transfer) process. The reducing property exhibited by metal-metal salt combinations proceeds through the transfer of one electron from the metal surface to the substrate. In such combinations the elementary metal 
Table 1. Reductive debromination of vic-dibromides using a $\mathrm{CoCl}_{2} \cdot 6 \mathrm{H}_{2} \mathrm{O} /$ indium system

\begin{tabular}{|c|c|c|c|c|}
\hline Entry & Substrate & Product & $\begin{array}{l}\text { Reaction } \\
\text { time (h) }\end{array}$ & $\begin{array}{l}\text { Yield } \\
(\%)^{a, b}\end{array}$ \\
\hline 1 & & & 1.0 & 95 \\
\hline 2 & & & 1.5 & 91 \\
\hline 3 & & & 2.0 & 90 \\
\hline 4 & & & 3.0 & 88 \\
\hline 5 & & & 0.5 & 93 \\
\hline 6 & & & 1.0 & 94 \\
\hline 7 & & & 3.5 & 87 \\
\hline 8 & & & 0.5 & 92 \\
\hline 9 & & & 2.0 & 90 \\
\hline 10 & & & 3.0 & 89 \\
\hline 11 & & & 0.5 & 93 \\
\hline
\end{tabular}

${ }^{a}$ Isolated yields. ${ }^{b}$ The products are commercially available and were characterized by comparison of their spectral data with data on authentic samples.

part should be more electropositive than the metal part of the salt. We have demonstrated the utility of a $\mathrm{CoCl}_{2} \cdot 6 \mathrm{H}_{2} \mathrm{O}$ / indium system in effecting chemoselective debromination of vic-dibromides.

In conclusion, we have found that vic-dibromides treated with $\mathrm{CoCl}_{2} \cdot 6 \mathrm{H}_{2} \mathrm{O}$ /indium system in methanol are efficiently converted into the corresponding alkenes in high yields under mild conditions. Although the scope and limitations of this method have not been fully established, it is expected to be a useful and efficient alternative to the existing methods for the debromination of vic-dibromides.

Acknowledgments. This work was financially supported by Korea University.

\section{References}

1. Greene, T. W.; Wuts, P. G. M. Protective Groups in Organic Synthesis, 2nd edn.; New York, 1991.

2. (a) Buther, T. S.; Detty, M. R. J. Org. Chem. 1998, 63, 169. (b) Li, C. J.; Harpp, D. N. Tetrahedron Lett. 1990, 31, 6291. (c) Malanga, C.; Mannucci, S.; Lardicci, L. Tetrahedron 1998, 54, 1021. (d) Tanata, R.; Negoro, N.; Yanada, K.; Fujita, T. Tetrahedron Lett. 1996, 37, 9313. (e) Ranu, B. C.; Guchhait, S. K.; Sarkar, A. J. Chem. Soc. Chem. Commun. 1998, 2113. (f) Mathai, I. M.; Sching, K.; Miller, S. I. J. Org. Chem. 1970, 35, 1733.

3. (a) Baruah, M.; Hussain, A.; Prajapati, D.; Sanduhu, J. Chem. Lett. 1997, 789. (b) Blanchard, P.; Da Silva, A. D.; El Kortbi, M. S.; Fourrey, J. L.; Robert-Gero, M. J. Org. Chem. 1993, 58, 6567. (c) Orsini, F.; Leccioli, C. Tetrahedron: Asymmetry 1997, 8, 4011. (d) Orsini, F. J. Org. Chem. 1997, 62, 1159. (e) Orsini, F. Tetrahedron Lett. 1998, 39, 1425. (f) Orsini, F.; Pulici, M.; Vallarino, L. M. J. Organomet. Chem. 1995, 495, 1.

4. For review: (a) Nair, V.; Ros, S.; Jayan, C. N.; Pillia, B. S. Tetrahedron 2004, 60, 1959. (b) Lubineau, A.; Auge, J.; Queneau, Y. Synthesis 1994, 741. (c) Li, C. J. Tetrahedron 1996, 52, 5643. (d) Cintas, P. Synlett. 1995, 1087.

5. (a) Yoo, B. W.; Song, M. S.; Park, M. C. Synth. Commun. 2007, 37, 3089. (b) Yoo, B. W.; Park, M. C.; Shin, J. I. Bull. Korean Chem. Soc. 2009, 30, 1927. (c) Yoo, B. W.; Kim, S. H.; Kim, J. H. Bull. Korean Chem. Soc. 2010, 31, 2757. (d) Yoo, B. W.; Kim, J. H.; Yang, M. H. Bull. Korean Chem. Soc. 2010, 31, 791.

6. Han, J. H.; Choi, K. I.; Kim, J. H.; Yoon, C. M.; Yoo, B. W. Synth. Commun. 2006, 36, 415.

7. A typical procedure for the debromination of vic-dibromides is as follows: Indium powder $(230 \mathrm{mg}, 2.0 \mathrm{mmol})$ and $\mathrm{CoCl}_{2} 6 \mathrm{H}_{2} \mathrm{O}$ $(238 \mathrm{mg}, 1.0 \mathrm{mmol})$ are mixed in methanol $(4 \mathrm{~mL})$. The resulting mixture is sonicated in an ultrasonic cleaner ${ }^{9}$ for $0.5 \mathrm{~h}$ and a solution of the low-valent cobalt-indium complex is formed. 1,2Dibromo-1,2-diphenylethane $(170 \mathrm{mg}, 0.5 \mathrm{mmol})$ is then added to this solution and the reaction mixture is stirred for $2.0 \mathrm{~h}$ at room temperature. The solvent is removed under reduced pressure and the residue is extracted with ethyl acetate, washed with brine, and dried over anhydrous $\mathrm{Na}_{2} \mathrm{SO}_{4}$. The crude product is purified by silica gel column chromatography (hexane:ethyl acetate $=10: 1$ ) to afford trans-stilbene ( $81 \mathrm{mg}, 90 \%$ ).

8. (a) Hudlicky, T.; Sinai-Zingde, G.; Natchus, M. G. Tetrahedron Lett. 1987, 26, 5287. (b) Khurana, J. M.; Gogia, A.; Bankhwal, R. K. Synth. Commun. 1997, 27, 1801. (c) Yanada, R.; Bessho. K.; Yanada, K. Synlett 1995, 443.

9. Sonication was carried out in a BRANSONIC ultrasonic cleaner bath, which produced a $47 \mathrm{KHz}$ wave, with a fixed electrical power of 125 Watts. 